\title{
AVALIAÇÃO PRELIMINAR DAS CONDIÇÕES HIDROGEOLÓGICAS NA ÁREA DO MUNICÍPIO DE OURO PRETO, MG.
}

\author{
Quênia de Cássia Goulart Ferreira ${ }^{1}$, Luis de Almeida Prado Bacellar ${ }^{2}$
}

\begin{abstract}
RESUMO
O conhecimento da dinâmica natural e da qualidade das águas subterrâneas no município de Ouro Preto é ainda deficiente. Em vista disto, foi elaborado um banco de dados hidrogeológicos com o intuito de avaliar de forma preliminar o potencial hídrico subterrâneo desta área. A análise e tratamento dos dados secundários e primários obtidos permitiu a identificação de oito sistemas aqüíferos. O sistema do Grupo Itabira, onde se encontram as formações ferríferas da Formação Cauê, é o de maior potencial. Os sistemas em rochas do embasamento cristalino destacam-se pelo maior número de poços tubulares cadastrados. Análises de parâmetros físico-químicos e de elementos inorgânicos na água subterrânea revelaram que a maioria apresenta concentrações inferiores aos máximos permitidos pela legislação para água potável. Contudo, como o sistema de proteção sanitária dos poços se mostrou muitas vezes inadequado, é possível que haja alguma contaminação por elementos ou compostos não analisados e que deverão ser futuramente investigados.
\end{abstract}

Palavras-chaves: hidrogeologia, sistemas aqüíferos, hidroquímica, Ouro Preto.

\begin{abstract}
The knowledge of physical and chemical conditions of groundwater in the city of Ouro Preto is still deficient. Therefore, in this paper a hydrogeological database was made, in order to estimate the groundwater potential of the area. The analysis and processing of secondary and primary data allowed the identification of eight aquifer systems. The aquifer system of the Itabira Group, with iron formations, was considered the best, while the crystalline basement system has the highest number of registered wells. Analysis of physicalchemical parameters and inorganic elements in groundwater has revealed that most concentrations are below the maximum allowed by law for drinking water. owever, the sanitary protection of the wells is frequently inadequate and there are ossibly other contaminants, which should be further investigated.
\end{abstract}

Keywords: hydrogeology, aquifer systems, hydrochemistry, Ouro Preto.

\section{INTRODUÇÃO}

Como a área do município de Ouro Preto se caracteriza por uma elevada disponibilidade de recursos hídricos superficiais, a água subterrânea tem sido relativamente pouco explotada e, por conseqüência, pouco estudada. Recentemente, com o incremento da demanda e do grau de contaminação de parte dos recursos hídricos superficiais, o interesse pelas águas subterrâneas tem aumentado. Portanto, para melhorar a gestão da água, torna-se recomendável a elaboração de um estudo hidrogeológico que contemple os aspectos tanto qualitativos quanto quantitativos da água subterrânea e que permita definir os aqüíferos de maior potencial.

Neste sentido, foram compilados dados hidrogeológicos prévios, objetivando a criação de um banco de dados com todos os poços tubulares cadastrados no município, de forma a subsidiar uma caracterização hidrogeológica preliminar. Para complementar as informações sobre os aqüíferos, foram também levantadas todas as bacias hidrográficas na área, com séries históricas de dados hidrológicos. Este procedimento visou o emprego do método hidrológico para aprimoramento da caracterização hidrogeológica.

Considera-se que o produto final aqui gerado poderá ser útil para estabelecer a disponibilidade de água subterrânea na região, facilitar a locação de novos poços

tubulares e auxiliar futuros projetos de ordenamento territorial do município.

\section{CARACTERÍSTICAS DA ÁREA}

\section{Contexto Geológico}

Grande parte da área do município de Ouro Preto se insere no Quadrilátero Ferrífero (QF), que engloba quatro grandes unidades litoestratigráficas do Arqueano e do Paleoproterozóico (Marshak \& Alkmin 


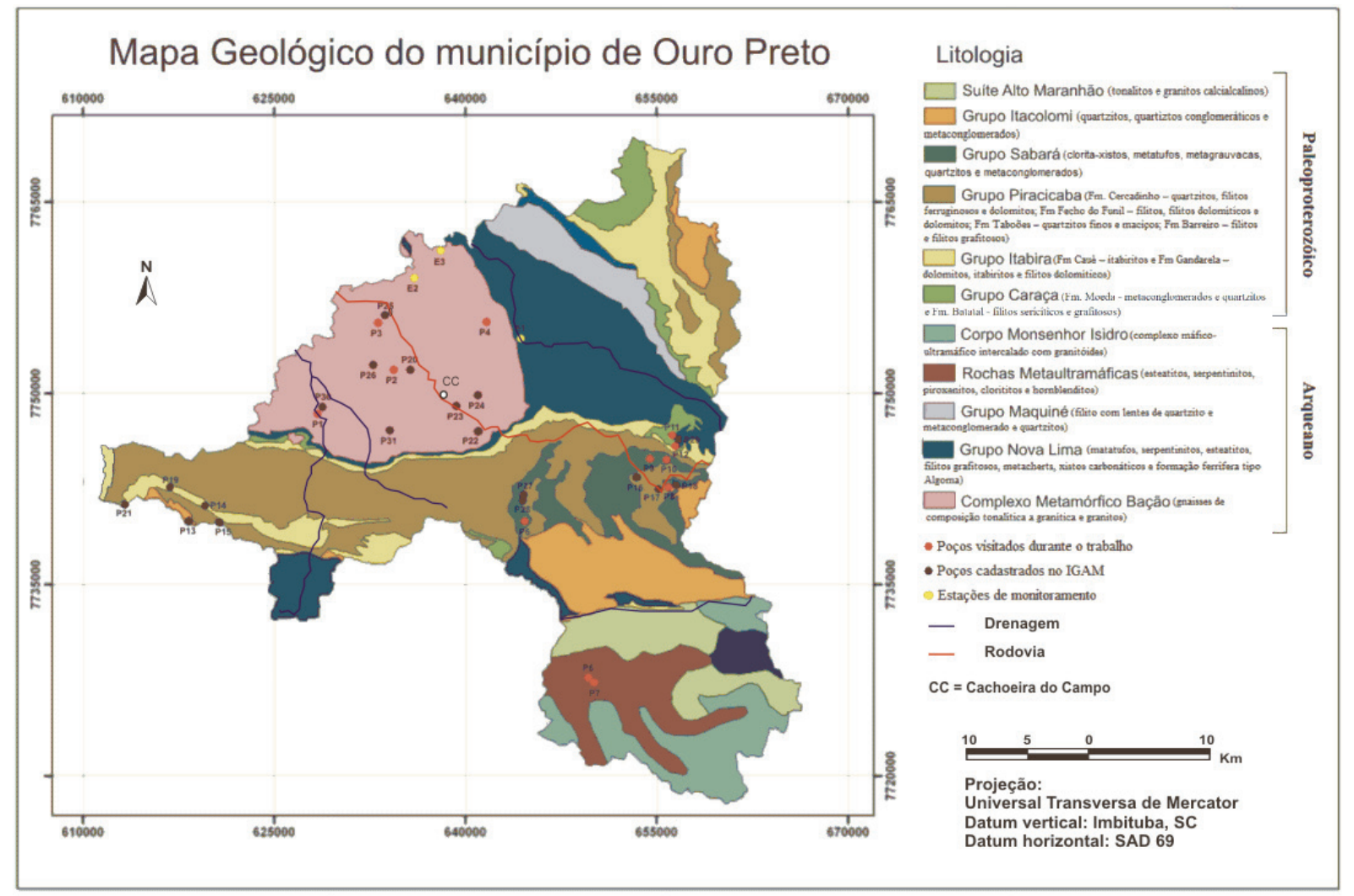

Figura 1: Mapa geológico da área do município de Ouro Preto/MG.

1989) (Figura 1): Complexo Metamórfico do Bação, Supergrupo Rio das Velhas, Supergrupo Minas e Grupo Itacolomi Ao sul do município e do QF, encontramse cartografadas pela CPRM (2009) as seguintes unidades: Unidades Metamáficas e Metaultramáficas, Corpo Monsenhor Isidro e Suíte Alto Maranhão. Estas unidades encontram-se deformadas e metamorfizadas em graus variáveis por diversos eventos tectônicos (Alkmim \& Marshak 1998). As unidades mais antigas, datadas do Arqueano, são as seguintes:

- Complexo Metamórfico Bação - composto basicamente por gnaisses de composição tonalítica a granítica e granitóides;

- Supergrupo Rio das Velhas (Dorr 1969) abrange o Grupo Nova Lima, subdividido em unidade ultramáfica (metatufos, serpentinitos, esteatitos, filitos grafitosos e metacherts) e unidade metassedimentar química (xistos carbonáticos, metacherts, formação ferrífera tipo Algoma e filitos grafitosos); e o Grupo Maquiné, constituído de filitos com lentes de quartzito, metaconglomerados e quartzitos;

- Rochas Metaultramáficas - abrangem esteatitos, serpentinitos, piroxenitos, lorititos e hornblenditos (CPRM 2009);

- Corpo Monsenhor Isidro - corresponde a um complexo máfico-ultramáfico intercalado com granitóides (CPRM 2009); sunidades, atribuídas ao Paleoproterozóico, são:
As unidades, atribuídas ao Paleoproterozóico, são:

- Suíte Alto Maranhão - composta, basicamente, por tonalitos e granitos calcialcalinos (CPRM 2009);

- Supergrupo Minas, formado, da base para o topo, pelas seguintes unidades estratigráficas (Dorr 1969, Alkmim \& Marshak 1998): 1) Grupo Caraça - composto por metaconglomerados e quartzitos (Formação Moeda), sobrepostos por filitos sericíticos e grafitosos da Formação Batatal; 2) Grupo Itabira - constituído pelas formações Cauê (itabiritos) e Gandarela (dolomitos, itabiritos e filitos dolomíticos); 3) Grupo Piracicaba - composto pela Formação Cercadinho (quartzitos e filitos ferruginosos), Formação Fecho do Funil (filitos, filitos dolomíticos e dolomitos), Formação Taboões (quartzitos finos e maciços) e Formação Barreiro (filitos e filitos grafitosos); 4) Grupo Sabará (Renger et al. 1994) -no topo da sequência, em discordância erosiva, e constituído por cloritaxistos, metatufos, metagrauvacas, quartzitos e metaconglomerados;

- Grupo Itacolomi - repousa em discordância sobre o Supergrupo Minas, sendo composto por quartzitos, quartzito conglomeráticos e metaconglomerados. 


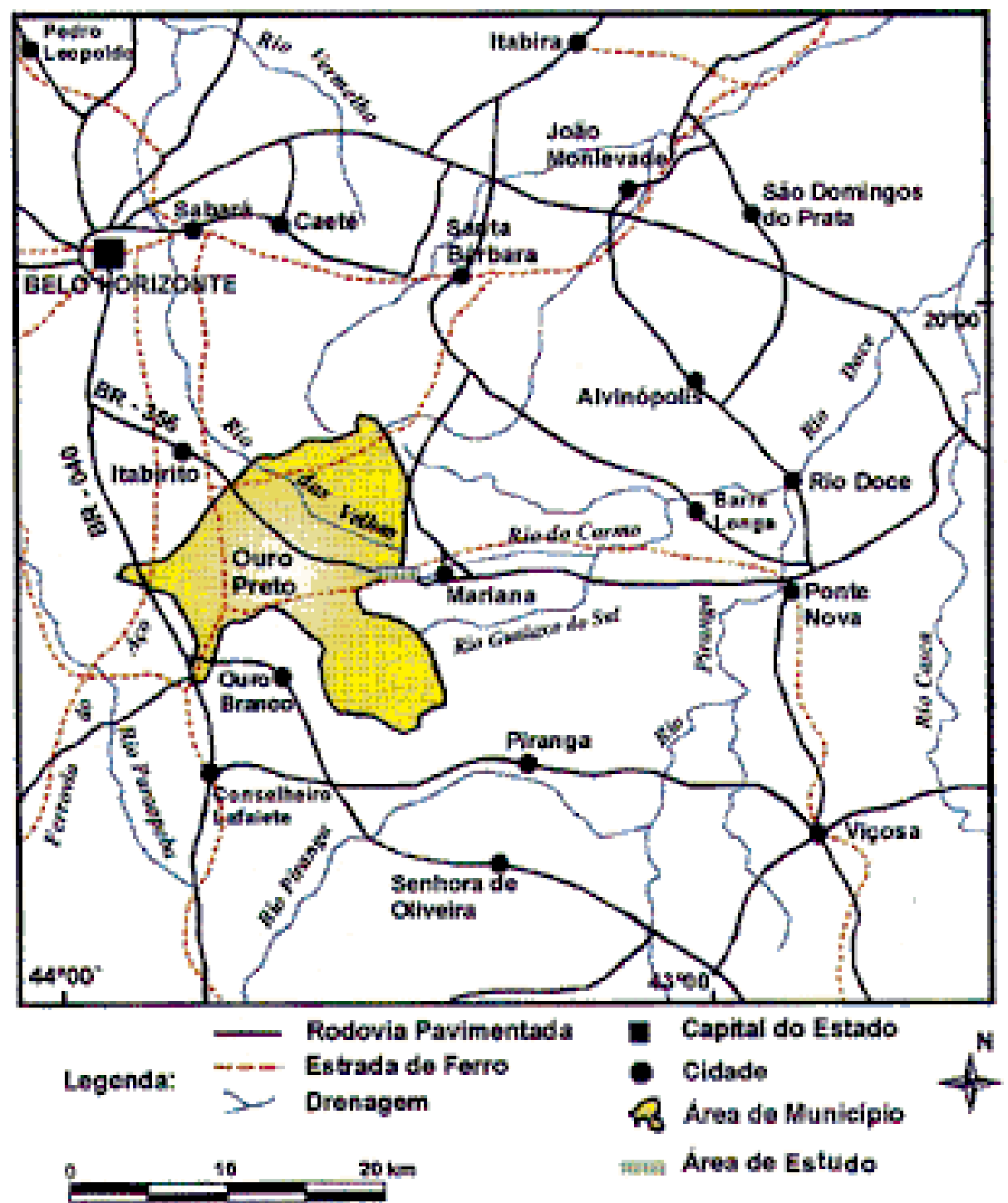

Figura 2: Mapa de localização do município de Ouro Preto/MG.

\section{Aspectos fisiográficos}

O município de Ouro Preto, com área de aproximadamente $1.245 \mathrm{~km} 2$ e população residente de 67.048 habitantes (IBGE 2007), se localiza no centro-sul de Minas Gerais, a sudeste de Belo Horizonte (Figura 2).

O relevo do município é diversificado, resultado da complexa natureza litológica e estrutural (Varajão 1991). As regiões mais elevadas e íngremes são sustentadas por quartzitos e formações ferríferas, de maior resistência ao intemperismo e à erosão, do Grupo Itacolomi e das formações Moeda e Cauê, do Supergrupo Minas (Varajão 1991). As regiões mais baixas, com relevo de mares de morros, têm os gnaisses como litotipo dominante (Varajão 1991). Os níveis intermediários são constituídos predominantemente por xistos, filitos e quartzitos friáveis dos supergrupos Minas e Rio das Velhas. O território do município é drenado por duas grandes bacias apartadas pela Serra de Ouro Preto: a do rio das Velhas (bacia do rio São Francisco) e a do rio Doce. A área está inserida na transição entre Mata Atlântica, com solos mais férteis, e o Cerrado, preponderante no Complexo do Bação, com solos pobres e muito lixiviados (Latossolos VermelhoAmarelos). Os tipos vegetacionais predominantes são as florestas semidecíduas, higrófilas e de galeria, campos rupestres e matas de candeia (Dutra et al. 2006). O clima esta inserido nos tipos Cwa e Cwb da classificação de Köppen. O Cwa predomina nas partes menos elevadas, como no Complexo Bação, com verões quentes e chuvosos e estação seca curta (Cruz, 1995), exibindo taxa pluviométrica média anual de $1.419 \mathrm{~mm}$ (Santos et al. 2002) e temperatura média de $27,9^{\circ}$. Já o Cwb ocorre nas regiões mais elevadas e é caracterizado por verões brandos (Cruz 1995) e maior índice pluviométrico médio (2.100 mm), aspectos característicos do clima tropical de altitude (RADAM BRASIL 1983). 


\section{MÉTODOS}

Os dados hidrogeológicos e hidrológicos foram obtidos a partir de diversas fontes: Serviço Municipal de Água e Esgoto de Ouro Preto (SEMAE), Instituto Mineiro de Gestão de Águas (IGAM), Companhia de Saneamento de Minas Gerais (COPASA), Agência Nacional de Águas (ANA), Companhia de Pesquisa de Recursos Minerais (CPRM). Dentre os poços tubulares cadastrados (total de 45), selecionaram-se onze onsiderados mais representativos das unidades litológicas, para uma campanha de coleta de água (entre 23 e 30/03/2009). A amostragem objetivou mensurar "in loco" os seguintes parâmetros físico-químicos: condutividade elétrica (CE), $\mathrm{pH}, \mathrm{Eh}$, sólidos totais dissolvidos (STD), temperatura, turbidez e oxigênio dissolvido (OD). Para tal, foram utilizados os seguintes aparelhos de campo: 1) multiparâmetro portátil (Myron, modelo Ultrameter 6P); 2) turbidímetro portátil (Hanna Instruments, modelo HI93703) e, ) oxímetro portátil (Digimed, modelo DM-4P). Também foram coletadas, em garrafas de polietileno de 1L, amostras de água na boca dos poços produtores para análise da alcalinidade e cloreto (pelo método Titulométrico) e de sulfato (pelo método Turbidimétrico). Uma terceira amostra foi filtrada em frascos de $50 \mathrm{~mL}$ para a análise de metais em ICP-OES, no Laboratório de Geoquímica Ambiental da UFOP. Seguindo as recomendações da APHA/AWWA/ WPCF (1992), para a coleta das amostras, fez-se o ambiente três vezes antes de armazená-las no frasco, e no caso da amostra filtrada, acrescentou-se três gotas de ácido nítrico (HNO3), para sua preservação em pH igual ou inferior a 2 . Para transporte, as amostras foram acondicionadas em recipiente com gelo para manutenção da temperatura a um valor igual ou inferior a $4^{\circ} \mathrm{C}$. Selecionaram-se cinco estações com séries históricas de monitoramento fluviométrico em bacias hidrográficas situadas no município objetivando o cálculo da transmissividade (T) média dos aquíferos pelo método hidrológico (Costa 2005). Para tal, assumiu-se que os aquíferos são livres e os rios efluentes e calculou-se o coeficiente de recessão $(\alpha)$ em hidrogramas com médias mensais empregandose a fórmula exponencial de Maillet (Custodio \& Lamas 1976, Dewandel et al. 2003):

$$
\mathrm{Qt}=\mathrm{Qo} \mathrm{e}^{-\mathrm{at}}
$$

\section{Onde:}

Qt e Qo: vazão $\left(\mathrm{m}^{3} / \mathrm{s}\right)$ no tempo t e no início da recessão, respectivamente.

$\alpha$ : Coeficiente de recessão (dias-1)

t: tempo desde o inicio da recessão (dias)

De posse do valor de $\alpha$ e assumindo-se um intervalo confiável de valores de coeficientes de armazenamento (Sy) tomados da bibliografia, estimaram-se os valores mínimos e máximos de transmissividade média dos aquíferos constituintes de cada bacia, utilizando-se do Modelo de Maillet (Dewandel et al. 2003), que tem como equação:
Onde:

$T=\frac{4 S y L^{2} \alpha}{\pi^{2}}$

Sy - coeficiente de armazenamento dos aquíferos livres (adm).

$\mathrm{L}=$ distância média canal-interflúvio na bacia.

Obteve-se o valor de L a partir de mapas topográficos em escala 1:50.000 das folhas Ouro Preto e Mariana, seguindo recomendações de Ferreira (2010). Os poços tubulares profundos com testes de aquífero ou de recuperação foram interpretados com o método de Cooper-Jacob (Custodio \& Llamas 1976). Para os testes de recuperação, foram seguidas as recomendações de Kresic (1997) quanto à correção do tempo. A integração e interpretação deste conjunto de dados possibilitaram a elaboração do mapa de sistemas aquíferos para a área do município, baseando-se em proposta anterior formulada pelo IGAM (2001).

\section{RESULTADOS}

Foram inventariados 45 poços tubulares profundos, distribuídos pela sede do município e seus distritos (Figura 1). Seus dados construtivos e hidrodinâmicos estão representados na tabela 1 .

Constatou-se que os poços tubulares concentramse em áreas do Complexo do Bação (embasamento cristalino) e na sede de Ouro Preto (especialmente no domínio do Grupo Piracicaba), em número de 19 (42\% do total) e 13 ( $29 \%$ do total) poços, respectivamente. Tal fato se deve à maior ocupação dessas áreas. Do total de poços cadastrados, 15 são utilizados para o abastecimento público, 6 por empresas de mineração e 24 para outros usos, com destaque para o industrial. Destaca-se que a maioria dos poços visitados é desprovida de adequada proteção sanitária, como laje de proteção e selo sanitário, favorecendo a contaminação dos aqüíferos. O ano de perfuração dos poços varia de 1953 a 2006 e a profundidade de 32 a 225 metros, estando os mais profundos situados nas minas a céu aberto em formações ferríferas do Grupo Itabira. Os métodos de perfuração mais empregados são o rotativo e a percussão e os equipamentos de bombeamento mais freqüentes são as bombas submersas ou de ar comprimido. As vazões variam de $0,06 \mathrm{~m}^{3} / \mathrm{h}$ a 280,00 $\mathrm{m}^{3} / \mathrm{h}$ e as vazões específicas entre 0,03 e $58,89 \mathrm{~m}^{3} /$ dia.m. Os filtros mais freqüentes são do tipo Nold, espiralado ou de PVC geomecânico e os pré-filtros são variados, como areia pérola, brita, pedrisco, dentre outros. Os tubos de revestimento mais comuns são de aço e, secundariamente, de PVC geomecânico. Também foram compilados dados químicos e físico-químicos disponibilizados nos relatórios de poços (Tabela 2), aos quais foram adicionados os resultados de análises feitas neste estudo em águas de onze poços tubulares representativos da área de estudo.

Constatou-se que a maioria dos parâmetros químicos se encontra dentro do padrão de potabilidade estabelecido pela Portaria 518, do Ministério da 
Tabela 1: Dados dos poços tubulares profundos

\begin{tabular}{|c|c|c|c|c|c|c|}
\hline Designação & $\begin{array}{l}\text { Localização/Ano } \\
\text { de perfuração }\end{array}$ & Geologia/Aquífero & $\begin{array}{c}\text { Diâmetro (pol)/ } \\
\text { Profundidade (m) }\end{array}$ & $\begin{array}{c}\text { Vazão (Q) } \\
\left(\mathrm{m}^{3} / \mathrm{h}\right)\end{array}$ & $\mathrm{NE} / \mathrm{ND}(\mathrm{m})$ & $\begin{array}{c}Q_{\text {esp }} \\
(\mathrm{I} / \mathrm{s} . \mathrm{m})\end{array}$ \\
\hline P1 & Enq Correia/- & Bacão/GF & $-/ 66$ & 5.4 & $-1-$ & - \\
\hline P3 & Coelhos/- & Bação/GF & -162 & - & $\frac{1}{-1-}$ & - \\
\hline P4 & Glaura/1975 & Bacão/GF & $4 / 53$ & 50,4 & $-1-$ & - \\
\hline 02 (P4) & Glaura/1993 & Bacão/GF & $4 /-$ & 50,4 & $-1-$ & - \\
\hline Poço 01 (P6) & S. Rita de OP/1997 & Metaultramáfica/- & $-1-$ & 110,0 & $-1-$ & - \\
\hline Poco 02 (P6) & S. Rita de OP/1997 & Metaultramáfica/- & $-1-$ & 120,0 & $-1-$ & - \\
\hline Poco 03 (P7) & S. Rita de OP/- & Metaultramáfica/- & $-1-$ & 5,1 & $-1-$ & - \\
\hline Morro do Gambá (P8) & Sede/- & Grupo Sabará/F & $6 / 103$ & - & $-/ 60$ & - \\
\hline M. S. Sebastião - 02 & Sede/1991 & Nova Lima/F & $-/ 87$ & 7,5 & $-/ 38$ & 0.054 \\
\hline M. S. Sebastião - 01 & Sede/ 1975 & Nova Lima/F & -1101 & 2,4 & $2 /-$ & - \\
\hline M. J. Mendes (P13) & Miguel Burnier/2000 & Itabira/GF & $8 / 152$ & 12,0 & $14 / / 32$ & 0,012 \\
\hline D. Maria Consuelo & Amarantina/2002 & Bação/F & $6 / 100$ & 1,0 & $5 / 60$ & 0,025 \\
\hline Ferteco Mineração & Miguel Burnier/2002 & Cauê/GF & $71 / 2 " / 140$ & 66,0 & $2 / 82$ & 0,218 \\
\hline Ferteco Mineração & Miguel Burnier/1995 & Cauê/GF & $6 / 150$ & 30,0 & $1 / 78$ & 0,218 \\
\hline Novelis 1 (P16) & Saramenha/- & Piracicaba/GF & $6 / 117$ & 97.9 & $5 / 41$ & 0.0007 \\
\hline Novelis 2 (P16) & Saramenha/1971 & Piracicaba/GF & $6 / 128$ & 186,6 & $6 / 18$ & 0,004 \\
\hline Novelis $3(\mathrm{P} 16)$ & Saramenha/1981 & Piracicaba/GF & $6 / 91$ & 149,3 & $2 / 28$ & 0.0015 \\
\hline Novelis 4 (P17) & Saramenha/1992 & Piracicaba/GF & $6 / 40$ & 0,3 & $8 / 36$ & 0,0009 \\
\hline Novelis 5 (P17) & Saramenha/1993 & Piracicaba/GF & $6 / 60$ & 0,2 & $21 / 45$ & 0,002 \\
\hline Novelis 6 (P17) & Saramenha /1993 & Piracicaba/GF & $6 / 42$ & 0,2 & $11 / 32$ & 0,002 \\
\hline Novelis 7 (P17) & Saramenha/1993 & Piracicaba/GF & $6 / 42$ & 0,06 & $10 / 31$ & 0.0008 \\
\hline Fundação Gorceix & Saramenha/2006 & Sabará/GF & $6 / 100$ & 3,0 & $16 / 60$ & 0,019 \\
\hline CVRD (P19) & Miguel Burnier/1999 & Cauê/GF & $97 / 8 " / 131$ & 280,0 & $1 / 21$ & 5,108 \\
\hline Pedreira Irmãos & Amarantina/1985 & Bacão/F & $6 / 42$ & 3,7 & $3 / 33$ & 0,082 \\
\hline CVRD & Miguel Burnier/2006 & Cauê/F & $10 / 225$ & 12,9 & $124 / 174$ & 0,071 \\
\hline Posto Dom Bosco & C. do Campo/2001 & Bacão/F & $-/ 60$ & 3,0 & $2 / 43$ & 0,107 \\
\hline Rodol Ltda (P23) & C. do Campo/- & Bacão/GF & $8 / 32$ & 4,7 & $3 / 16$ & 0,104 \\
\hline PMOP & Amarantina/1981 & Bação/F & $-/ 60$ & 11,9 & $2 / 20$ & 0,185 \\
\hline PMOP & Amarantina/1982 & Bacão/GF & $-/ 82$ & 11,4 & $4 / 42$ & 0,085 \\
\hline PMOP & Amarantina/ 1990 & Bacão/GF & $-/ 70$ & 7,4 & $3 / 29$ & 0,078 \\
\hline Terminal Sul & Terminal Sul/1986 & Bação/F & $-/ 105$ & 1,6 & $8 / 72$ & 0,007 \\
\hline Reitoria/UFOP & Sede/1985 & Piracicaba/GF & $-/ 80$ & 13,2 & $6 / 45$ & 0,094 \\
\hline PMOP & S. A. do Leite/1985 & Bação/GF & $-/ 80$ & 29,3 & $2 / 26$ & 0,340 \\
\hline Saramenha - Novelis & Saramenha/1985 & Piracicaba/GF & $-/ 150$ & 23,3 & $0 / 66$ & 0,098 \\
\hline Saramenha - Novelis & Saramenha/1985 & Piracicaba/GF & $-/ 80$ & 13.2 & $6 / 45$ & 0.094 \\
\hline Saramenha - Novelis & Saramenha/1985 & Piracicaba/GF & $-/ 80$ & 29,3 & $2 / 26$ & 0,340 \\
\hline PMOP & Barra/Sede/1953 & Piracicaba/GF & $-/ 53$ & 11,9 & $0 / 19$ & 0,174 \\
\hline PMOP & C. do Campo/1971 & Bação/GF & $6 / 80$ & 7,9 & $2 / 38$ & 0,061 \\
\hline PMOP & Tabuões/1990 & Bação/GF & $6 / 100$ & - & - & - \\
\hline PMOP & Glaura/1990 & Bacão/GF & $-/ 62$ & 5,9 & $1 / 35$ & 0.048 \\
\hline
\end{tabular}

(-) Dados não encontrados; PMOP: Prefeitura Municipal de Ouro Preto; F - porosidade fissural; G -

porosidade intergranular; NE - nível estático; ND - nível dinâmico; Qesp - vazão específica

Saúde (MS, 2004), com exceção do arsênio no poço de Engenheiro Corrêa (P1, no Complexo Bação) e do ferro, em poço localizado no Grupo Sabará (Tabela 2).

A tentativa de estabelecer correlações entre a hidroquìmica, a litologia e a geomorfologia foi insatisfatória, provavelmente em conseqüência do pequeno volume de dados e da incerteza quanto aos resultados das análises compiladas em relatórios, feitas em laboratórios distintos e com métodos diversos. Para cálculo dos parâmetros hidrodinâmicos com o método de Cooper \& Jacob, foram selecionados 13 (treze) poços tubulares profundos com disponibilidade de dados, sendo 12 (doze) com testes de produção e 1 (um) com teste de aqüífero. Nos testes de produção empregaram-se dados de ensaio de recuperação do nível para a determinação da transmissividade. Em 6 (seis) poços a recuperação exibiu comportamento não linear em gráficos monologarítmicos, invalidando a aplicação do método. Tal comportamento pode decorrer de problemas de execução do teste ou da não conformidade do aquífero às condições requeridas pelo método (Custodio \& Llamas 1976).

Somente no poço com teste de aqüíferos, situado na mineração Ferteco, nos itabiritos da Formação Cauê (Poço 15), foi possível determinar a transmissividade e o coeficiente de armazenamento em dois poços de observação. A transmissividade e o coeficiente de armazenamento revelaram valores de 50,6 e $59,8 \mathrm{~m} 2 / \mathrm{d}$ e 0,00079 e

0,00070, respectivamente (Ferreira 2009), estes típicos de aqüíferos confinados.

Os resultados dos testes assinalaram maiores valores de transmissividade para os poços no Grupo Itabira $(6,9$ a $59,8 \mathrm{~m} 2 / \mathrm{d}$ - Tabela 3), especificamente na Formação Cauê, evidenciando a boa capacidade de explotação de água subterrânea nos itabiritos, especialmente nas áreas de mineração de ferro, onde o processo supergênico de lixiviação que conduziu à formação do minério friável também promoveu o aumento na porosidade efetiva das rochas.

Valores também expressivos de T (entre 0,8 e 12,1 $\mathrm{m}^{2} /$ dia), porém menores que aqueles obtidos para as formações ferríferas, foram encontrados para os poços no Complexo do Bação. Os poços em unidades com predomínio de litologias de baixa condutividade hidráulica (xistos e filitos), pertencentes aos grupos Piracicaba ou Sabará, são, conseqüentemente, os de menor transmissividade $(0,1$ a $0,5 \mathrm{~m} 2 / \mathrm{d})$. Em face da carência de testes de campo, optou-se pela determinação adicional da transmissividade dos aqǘferos pelo método hidrológico (Costa 2005, Ferreira 2009). Foram utilizados dados de cinco estações de monitoramento 
Tabela 2: Dados físico-químicos da água de poços tubulares

\begin{tabular}{|c|c|c|c|c|c|c|c|c|c|}
\hline Local & $\begin{array}{l}\text { Temp. } \\
\left({ }^{\circ} \mathrm{C}\right)\end{array}$ & $\mathrm{CE}(\mu \mathrm{s} / \mathrm{cm})$ & $\begin{array}{c}\text { STD } \\
(\mathrm{mg} / \mathrm{L})\end{array}$ & $\mathrm{pH}$ & $\begin{array}{c}\text { OD } \\
(\mathrm{mg} / \mathrm{L})\end{array}$ & $\begin{array}{l}\text { Nitrato } \\
(\mathrm{mg} / \mathrm{L})\end{array}$ & $\begin{array}{l}\text { Sulfato } \\
(\mathrm{mg} / \mathrm{L})\end{array}$ & $\begin{array}{l}\text { Cloreto } \\
(\mathrm{mg} / \mathrm{L})\end{array}$ & $\begin{array}{c}\text { Alcalinidade } \\
(\mathrm{mg} / \mathrm{L})\end{array}$ \\
\hline Limite Portaria 518 Anvisa & - & - & 1000,0 & - & - & 10,0 & 250 & 250 & - \\
\hline Engenheiro Correa $(\mathrm{P} 1)^{*}$ & 22,0 & 53,67 & 32,3 & 6,08 & 6,23 & 1,1 & 1,61 & 10,01 & 28,51 \\
\hline Amarantina (P2) * & 23,0 & 64,23 & 38,7 & 6,36 & 5,63 & 0,2 & 1,97 & 5,25 & 45,20 \\
\hline Coelhos (P3) * & 22,5 & 120,30 & 72,4 & 6,91 & 4,89 & 0,8 & 1,79 & 7,51 & 76,49 \\
\hline Glaura-Poço $01(\mathrm{P} 4)^{*}$ & 21,1 & 85,91 & 51,8 & 6,81 & 4,75 & 0,8 & 1,79 & 13,01 & 34,77 \\
\hline Glaura - Poço $02(\mathrm{P} 4)^{*}$ & 21,1 & 126,90 & 76,8 & 7,30 & 4,64 & 0,2 & 1,69 & 4,50 & 76,49 \\
\hline Rodrigo Silva (P5) * & 20,2 & 206,90 & 127,1 & 7,58 & 3,17 & 0 & 2,06 & 6,51 & 146,00 \\
\hline $\begin{array}{l}\text { Santa Rita de Ouro Preto - Poço } 02 \\
(\mathrm{P} 6)^{*}\end{array}$ & 22,6 & 136,60 & 82,3 & 6,24 & 5,56 & 1,7 & 1,97 & 11,01 & 52,85 \\
\hline $\begin{array}{c}\text { Santa Rita de Ouro Preto - Poço } 03 \\
(\mathrm{P} 7)^{*}\end{array}$ & 21,3 & 108,60 & 65,2 & 6,60 & 5,81 & 0,6 & 2,96 & 7,76 & 72,32 \\
\hline Morro do Gambá (P8) * & 21,8 & 10,61 & 6,4 & 5,74 & 4,72 & 0,6 & 1,88 & 4,25 & 14,60 \\
\hline Antiga Febem - Cabeças (P9) * & 19,8 & 100,80 & 61,0 & 6,62 & 4,16 & 0,5 & 1,43 & 6,51 & 74,41 \\
\hline $\begin{array}{l}\text { Morro São Sebastião - Poço } 02 \\
(\mathrm{P} 11)^{*}\end{array}$ & 20,1 & 64,14 & 38,7 & 6,73 & 5,57 & 0,3 & 8,55 & 5,01 & 51,46 \\
\hline $\begin{array}{l}\text { Miguel Burnier - Mineração J. } \\
\text { Mendes (P13) }\end{array}$ & - & 5,60 & 2,0 & 6,88 & - & 0,10 & 1,00 & 0,40 & - \\
\hline $\begin{array}{c}\text { Miguel Burnier - Ferteco Mineração } \\
\text { S.A (P14) }\end{array}$ & 23,0 & 107,90 & - & 8,36 & 6,20 & 0,04 & 1,00 & 0,20 & 62,12 \\
\hline $\begin{array}{l}\text { Miguel Burnier - Ferteco Mineração } \\
\text { S.A (P15) }\end{array}$ & 18,0 & 107,80 & - & 8,19 & 6,00 & 0,04 & 1,00 & 1,50 & 60,60 \\
\hline Sede - Fundação Gorceix (P18) * & - & 18,90 & 10,0 & 6,57 & - & $<0,10$ & $<$ L.Q & 1,80 & - \\
\hline M. Burnier CVRD (P19) & - & - & 72,0 & 5,96 & - & 0,40 & 2,00 & 1,50 & - \\
\hline $\begin{array}{c}\text { Amarantina - Pedreira Irmãos } \\
\text { Machado (P20) }\end{array}$ & - & - & 77,0 & 5,87 & - & 0,03 & 0,01 & 0,03 & - \\
\hline $\begin{array}{c}\text { Miguel Burnier - CVRD Mina da } \\
\text { Fábrica (P21) }\end{array}$ & - & 45,90 & - & 6,69 & - & 0,05 & 1,54 & 2,00 & 29,00 \\
\hline $\begin{array}{l}\text { Cachoeira do Campo - Rodol Ltda } \\
\text { (P23) }\end{array}$ & 22,0 & 45,90 & 70,6 & 6,69 & 6,20 & - & $<1,00$ & 1,40 & 59,59 \\
\hline 申laura (P24) & 21,8 & 43,80 & 28,4 & 7,06 & 6,50 & - & $<1,00$ & 3,92 & 19,51 \\
\hline Coelhos (P25) & 23,0 & 103,70 & 67,0 & 6,78 & 6,70 & - & $<1,00$ & 3,92 & 79,68 \\
\hline Riacho Amarantina (P26) & 23,8 & 70,40 & 45,6 & 6,78 & 5,10 & - & $<1,00$ & 1,96 & 58,54 \\
\hline Rodrigo Silva (P27) & 20,7 & 27,10 & 17,4 & 6,72 & 6,70 & - & $<1,00$ & 2,94 & 26,02 \\
\hline Sistema São Sebastião (P28) & 20,5 & 48,00 & 31,3 & 6,30 & 6,10 & - & $<1,00$ & 1,96 & 35,78 \\
\hline Sistema São Sebastião (P28) & 20,0 & 113,00 & 140,5 & 6,40 & - & - & 3,83 & 0,22 & 43,80 \\
\hline Engenheiro Correa (P29) & 19,1 & 41,90 & 27,6 & 6,24 & 5,90 & - & $<1,00$ & 4,41 & 19,51 \\
\hline Santo Antônio do Leite (P30) & 18,8 & 7,70 & 4,9 & 6,58 & 6,40 & - & 16,36 & 3,92 & 61,79 \\
\hline Poço Novelis & 21,0 & 153,00 & 153,0 & 6,90 & - & - & 3,12 & 2,57 & 79,00 \\
\hline Poço UFOP - Parque Metalúrgico & 19,0 & 64,40 & 64,4 & 5,80 & - & - & $<1,00$ & 3,19 & - \\
\hline Poço da Barra & 19,0 & 94,90 & 94,9 & 6,00 & - & - & $<1,00$ & 3,22 & 22,90 \\
\hline
\end{tabular}

* Análises feitas neste trabalho; (-) Dados não quantificados; LQ - Limite de quantificação

fluviométrico, quatro situadas na bacia do alto rio das Velhas e uma na bacia do ribeirão do Carmo (na bacia do rio Doce). A determinação dos coeficientes de recessão em hidrogramas anuais com médias mensais possibilitou o cálculo da transmissividade pelo Modelo de Maillet (Tabela 4). A grande diversidade litológica das bacias investigadas dificulta a associação entre a litologia e a transmissividade calculada com este método (Tabela 4). Contudo, o maior valor de transmissividade (12,4 m2/d) foi registrado na estação Fazenda Maracujá, que drena em sua maior parte o Complexo do Bação. Por outro lado, as bacias que drenam especialmente xistos e filitos (estações Fazenda Água Limpa e São Caetano de Mariana) apresentam transmissividades menores (Tabela 4).

\section{SISTEMAS AQUÍFEROS}

Com base nas unidades hidroestratigráficas propostas pelo IGAM (2001) para a região do Alto Rio das Velhas, em trabalhos realizados no Quadrilátero Ferrífero (Sobreiro Neto et al. 2001, Silva et al. 1994) e nos dados obtidos neste trabalho, foi possível a identificação de oito sistemas aqüíferos no município (Figura 3):

- Sistema aqüífero Complexo Metamórfico do Bação/Suíte Alto Maranhão - Apresenta o maior número de poços tubulares no município, o que se deve à densa ocupação dos terrenos, especialmente no domínio do Complexo do Bação, e à reduzida disponibilidade de recursos hídricos 
Tabela 3: Dados dos testes de recuperação de níveis.

\begin{tabular}{|c|c|c|c|c|c|c|c|}
\hline Poço & Local & Unidade & $\begin{array}{c}\text { Vazão } \\
\left(\mathbf{m}^{3 / \text { dia }}\right)\end{array}$ & $\begin{array}{c}\text { Duração do } \\
\text { bombeamento } \\
(\mathbf{m i n})\end{array}$ & $\begin{array}{c}\text { Duração da } \\
\text { recuperação } \\
(\mathbf{m i n})\end{array}$ & $\begin{array}{c}\text { Rebaixamento } \\
(\mathrm{m})\end{array}$ & $\begin{array}{c}\text { Transmissi- } \\
\text { vidade (m²/dia) }\end{array}$ \\
\hline $\begin{array}{c}\text { Mineração J. } \\
\text { Mendes }\end{array}$ & $\begin{array}{c}\text { Miguel } \\
\text { Burnier }\end{array}$ & $\begin{array}{c}\text { Grupo } \\
\text { Itabira }\end{array}$ & 288,0 & $1200\left(^{*}\right)$ & 330 & 7,6 & 6,9 \\
\hline $\begin{array}{c}\text { Maria } \\
\text { Consuelo }\end{array}$ & Amarantina & $\begin{array}{c}\text { Complexo } \\
\text { Bação }\end{array}$ & 123,5 & $1872\left(^{*}\right)$ & 480 & 20,0 & 1,1 \\
\hline $\begin{array}{c}\text { Novelis } \\
\text { Poço 07 }\end{array}$ & Sede & $\begin{array}{c}\text { Grupo } \\
\text { Piracicaba? }\end{array}$ & 1,4 & 300 & 300 & 3,5 & 0,1 \\
\hline $\begin{array}{c}\text { Fundação } \\
\text { Gorceix }\end{array}$ & Sede & $\begin{array}{c}\text { Grupo } \\
\text { Piracicaba? }\end{array}$ & 72,0 & 1440 & 120 & 26,0 & 0,5 \\
\hline $\begin{array}{c}\text { Pedreira } \\
\text { Irmãos } \\
\text { Machado }\end{array}$ & Amarantina & $\begin{array}{c}\text { Complexo } \\
\text { Bação }\end{array}$ & 211,2 & 1440 & 30 & 3,2 & 12,1 \\
\hline $\begin{array}{c}\text { Auto Posto } \\
\text { Dom Bosco }\end{array}$ & $\begin{array}{c}\text { Cachoeira do } \\
\text { Campo }\end{array}$ & $\begin{array}{c}\text { Complexo } \\
\text { Bação }\end{array}$ & 105,4 & $1498\left(^{*}\right)$ & 240 & 25,5 & 0,8 \\
\hline
\end{tabular}

$\left({ }^{*}\right)$ - Correção do tempo de bombeamento (Kresic, 1997), em poços com vazão variável.

Tabela 4: Dados de coeficiente de recessão $(\alpha)$ e de transmissividade $(T)$ obtidos com o método hidrológico.

\begin{tabular}{|c|c|c|c|c|c|c|c|c|}
\hline \multirow{2}{*}{ Estação | } & \multirow{2}{*}{$\begin{array}{l}\text { Coordenadas da } \\
\text { estação }\end{array}$} & \multirow{2}{*}{$\begin{array}{c}\text { Período de } \\
\text { Monitoramento }\end{array}$} & \multirow{2}{*}{$\begin{array}{l}\text { Unidade Geológica } \\
\text { Predominante }\end{array}$} & \multirow{2}{*}{$\alpha\left(d^{-1}\right)$} & \multirow{2}{*}{$\begin{array}{l}\text { Largura } \\
\text { dos } \\
\text { canais } \\
\text { (m) }\end{array}$} & \multicolumn{3}{|c|}{$\mathrm{T}\left(\mathrm{m}^{2} / \mathrm{dia}\right)$} \\
\hline & & & & & & Mínima & Máxima & Média \\
\hline $\begin{array}{c}\text { Fazenda } \\
\text { Água Limpa } \\
(\mathrm{E} 1)\end{array}$ & $\begin{array}{l}20^{\circ} 18^{\prime} 19^{\prime \prime} \\
43^{\circ} 36^{\prime} 59^{\prime \prime}\end{array}$ & $1957-1993$ & $\begin{array}{c}\text { Grupo Piracicaba e } \\
\text { Complexo Metamórfico } \\
\text { Bação }\end{array}$ & 0,00313 & 221,5 & 0,6 & 18,7 & 9,7 \\
\hline $\begin{array}{l}\text { Fazenda } \\
\text { Água Limpa } \\
\text { - Jusante } \\
\text { (E1) }\end{array}$ & $\begin{array}{l}20^{\circ} 18^{\prime} 19^{\prime \prime} \\
43^{\circ} 36^{\prime} 59^{\prime \prime}\end{array}$ & $1995-2006$ & $\begin{array}{c}\text { Grupo Piracicaba e } \\
\text { Complexo Metamórfico } \\
\text { Bação }\end{array}$ & 0,00285 & 221,5 & 0,6 & 17,0 & 8,8 \\
\hline $\begin{array}{c}\text { Fazenda } \\
\text { Maracujá } \\
(\mathrm{E} 2)\end{array}$ & $\begin{array}{l}20015^{\prime} 46^{\prime \prime} \\
43^{\circ} 41^{\prime} 51^{\prime \prime}\end{array}$ & $2001-2006$ & $\begin{array}{c}\text { Complexo Metamórfico } \\
\text { Bação e Grupo } \\
\text { Piracicaba }\end{array}$ & 0,00628 & 208,5 & 1,1 & 33,2 & 17,1 \\
\hline $\begin{array}{c}\text { Fazenda } \\
\text { Vertentes } \\
\text { (E3) }\end{array}$ & $\begin{array}{l}20^{\circ} 14^{\prime} 26^{\prime \prime} \\
43^{\circ} 40^{\prime} 56^{\prime \prime}\end{array}$ & $2001-2006$ & $\begin{array}{c}\text { Grupo Nova Lima e } \\
\text { Piracicaba e Complexo } \\
\text { Bação }\end{array}$ & 0,00404 & 221,5 & 0,8 & 24,1 & 12,4 \\
\hline $\begin{array}{c}\text { São } \\
\text { Caetano de } \\
\text { Mariana } \\
\end{array}$ & $\begin{array}{l}20^{\circ} 21^{\prime} 00^{\prime \prime} \\
43^{\circ} 22^{\prime} 00^{\prime \prime}\end{array}$ & $1931-1965$ & $\begin{array}{c}\text { Grupo } \\
\text { Piracicaba }\end{array}$ & 0,00206 & 217,9 & 0,30 & 11,7 & 6,0 \\
\hline
\end{tabular}

superficiais (Costa \& Bacellar 2007). Possui em geral produtividade baixa, sendo subdividido em dois tipos de aqǘferos: um fissural, na rocha alterada, e um poroso, no manto de intemperismo (IGAM 2001, Sobreira Neto et al. 2001), muito desenvolvido nestas unidades de relevo mais suave. Os aqüíferos fraturados normalmente apresentam maiores valores de condutividade hidráulica e menores coeficientes e armazenamento (IBRAM 2003). Na bacia hidrográfica com predomínio deste sistema (Fazenda Maracujá) foram estimados valores de transmissividade mínima de $1,1 \mathrm{~m}^{2} /$ dia e máxima de 33,2 $\mathrm{m}^{2} / \mathrm{dia}$ (Tabela 4 ) e em testes de recuperação para três poços as transmissividades variaram entre 0,8 e $12,1 \mathrm{~m}^{2} /$ dia (Tabela 3 ). Os poços apresentam vazão média de $13,9 \mathrm{~m}^{3} / \mathrm{h}$ e vazão específica de $8,6 \mathrm{~m}^{3} /$ dia.m.;

- Sistema aqüífero do Grupo Nova Lima - Tido como de produtividade baixa a muito baixa (IGAM 2001), e subdivido em aqüíferos em formações ferríferas, de pequena extensão, e em aquicludes e aquitardos em xistos alterados (Sobreiro Neto et al. 2001). A aplicação do método hidrológico em bacia com predomínio desta unidade (Fazenda
Vertentes, tabela 4), resultou em valores de transmissividade variando entre $0,8 \mathrm{~m}^{2} /$ dia e 24,1 $\mathrm{m}^{2} /$ dia). Em dois poços tubulares, os valores de vazão foram de 7,5 e 2,4 m3/h e o único valor de vazão específica foi de $4,7 \mathrm{~m}^{3} /$ dia.m.;

- Sistema aqüífero do Grupo Maquiné - composto principalmente de quartzitos e micaxistos, de porosidade fissural, considerados como de médio potencial hídrico (IGAM 2001). Na área do município, não há poços cadastrados nesta unidade, que aflora em áreas pouco habitadas e com boa disponibilidade de cursos d'água superficiais;

- Sistema aqüífero das Rochas Metaultramáficas e Corpo Monsenhor Isidro - Não foram encontradas informações hidrogeológicas sobre estas áreas em domínios de rochas máficas e ultramáficas, havendo apenas dados de três poços situados no distrito de Santa Rita, com vazão de produção entre 0,2 a $5,0 \mathrm{~m}^{3} / \mathrm{h}$ (Tabela 1). As águas deste sistema tendem a ter composição mais rica em ferro e magnésio e outros elementos químicos associados;

- Sistema aqüífero do Grupo Caraça - Não há cadastro de poços neste sistema no município, 


\section{Mapa dos Sistemas Aquíferos do Município de Ouro Preto}

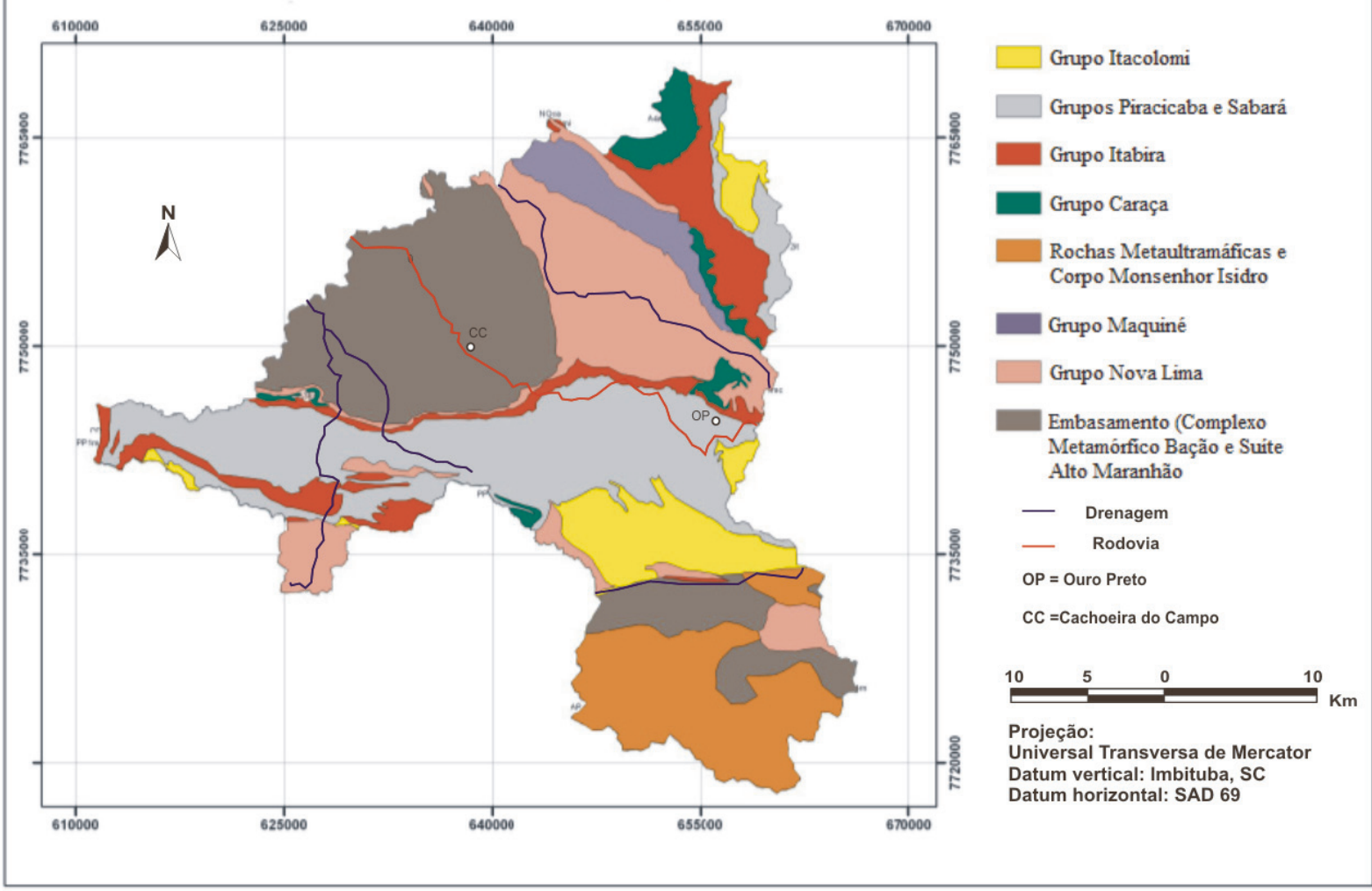

Figura 3: Mapa de Sistemas Aquiferos da área do município de Ouro Preto/MG.

mas de acordo com a proposta do IGAM (2001), pode-se subdividi-lo em aqüíferos fraturados nos quartzitos da Formação Moeda, e em aquitardos nos filitos da Formação Batatal. Na Formação Moeda a transmissividade é variável, às vezes muito alta, alcançando $600 \mathrm{~m} 2 / \mathrm{d}$ (Bertachini 1994);

- Sistema aqüífero do Grupo Itabira - pode ser subdividido em dois aqüíferos: 1) associados aos itabiritos da Formação Cauê e, 2) relacionados aos dolomitos da Formação Gandarela. O primeiro é um importante reservatório de águas subterrâneas, especialmente quando a lixiviação, promovida pelo processo supergênico, é intensa, resultando em aqüíferos com elevada capacidade de armazenamento e condutividade (Silva et al. 1994, IGAM 2001). Já os dolomitos constituem um aqüífero do tipo cárstico, heterogêneo e muito anisotrópico, até porque seu grau de carstificação é variável. Em relação às propriedades hidrodinâmicas, Silva et al. (1994) afirmam que as transmissividades variam de $50 \mathrm{~m}^{2} /$ dia a $1500 \mathrm{~m}^{2} /$ dia e os coeficientes de armazenamento entre 0,15 e $1 \times 106$, configurando aqüíferos livres a confinados. A interpretação de testes de bombeamento e recuperação (tabela 3) revelou valores de transmissividade para o Grupo Itabira entre 6,9 e $59,8 \mathrm{~m}^{2} /$ dia e de coeficiente de armazenamento de 0,0007;
- Sistema aqüífero dos grupos Piracicaba e Sabará - Abrange os aquitardos associados aos xistos e os aqüíferos nas unidades quartzíticas. Os aqüíferos são granulares e fissurais, com elevada porosidade e permeabilidade, apresentando localizadamente valores elevados de coeficiente de armazenamento, como indicam alguns dados hidrodinâmicos na Formação Cercadinho do Grupo Piracicaba (Sobreiro Neto et al. 2001, Silva et al. 1994). O método hidrológico indicou valores de transmissividade máximos entre 11,7 e $8,7 \mathrm{~m}^{2} /$ dia e mínimos de 0,4 e $0,6 \mathrm{~m}^{2} /$ dia (estações Fazenda Água Limpa e São Caetano de Mariana, Tabela 4). Este sistema é o segundo em número de poços tubulares cadastrados (13 poços), que apresentam vazão e vazão específica entre $0,1 \mathrm{e}$ $186,6 \mathrm{~m}^{3} / \mathrm{h}$ e 1,6 e $29,4 \mathrm{~m}^{3} /$ dia.m, respectivamente;

- Sistema aqüífero do Grupo Itacolomi - De acordo com o IGAM (2001), este sistema aqüífero possui potencial hídrico médio, sendo formado por aqüíferos fraturados, geralmente com elevados coeficientes de transmissividade. Nenhum os poços cadastrados encontra-se neste sistema.

\section{CONCLUSÕES}

Há carência de informações sobre os recursos hídricos subterrâneos no município de Ouro Preto, uma vez que estão cadastrados apenas 45 poços tubulares 
profundos num território de $1.245 \mathrm{~km}^{2}$. Estes poços encontram-se desigualmente distribuídos, com maior concentração nos domínios do Complexo do Bação e dos grupos Piracicaba e Sabará, com 19 e 13 poços, respectivamente. Com base nos dados de estudos realizados em escala regional e naqueles obtidos neste trabalho, dividiu-se a área em oito sistemas aqüíferos. O sistema do grupo Itabira foi considerado o de maior disponibilidade hídrica subterrânea. Contudo, mais informações são necessárias para confirmar a classificação e hierarquização proposta os sistemas aqüíferos. A análise de dados indica não haver problemas graves de contaminação nos poços ubulares cadastrados, pois os parâmetros químicos e físico-químicos atendem, de modo geral, à norma de potabilidade vigente no país. Contudo, as duas exceções encontradas devem ser mais bem analisadas. É premente ainda que se faça uma readequação dos poços com a instalação de medidas de proteção sanitária, para evitar a possibilidade de contaminação. O método hidrológico demonstrou ser uma ferramenta adicional adequada para estimar a transmissividade de aqüíferos de regiões desprovidas de poços com dados de testes de bombeamento de campo. Sugere-se que esta análise hidrogeológica preliminar seja continuada, incorporando-se um inventário pormenorizado de pontos d'agua (cisternas, nascentes, novos poços cadastrados, etc.), com o intuito de validar a classificação proposta de sistemas aqüíferos.

\section{AGRADECIMENTOS}

Agradecimentos ao CNPQ (Processo 307132/20080) e à FAPEMIG (Projeto EDT 3000/06 e PPMII), pelo apoio financeiro, ao professor Jorge Carvalho de Lena, do LGqA/DEGEO/UFOP), e às entidades que contribuíram para a realização deste trabalho, em especial o SEMAE de Ouro Preto e o IGAM.

\section{REFERENCIAS BIBLIOGRÁFICAS}

ALKMIM F.F. \& MARSHAK S. 1998. Transamazonian orogeny in the Southern São Francisco Craton region, Minas Gerais, Brazil: evidence for Paleoproterozoic collision nd collapse in the Quadrilátero Ferrífero. Precambrian Research, 90: 29-58

APHA/AWWA/WPCF, 1992. Standard Methods for the Examination of Water and Wastewater, 18th edition. American Public Health Association/American Water Works Association/Water Pollution Control Federation, Washington, DC

BERTACHINI A. C. 1994. Hidrogeologia e desaguamento da Mina de Águas Claras. In: Congr. Bras. Águas Subterrâneas, 8, Recife, Anais...: ABAS/DNPM/CPRM, p 274-283.

COSTA F.M. 2005. Análise por métodos hidrológicos e hidroquímicos de fatores condicionantes do potencial hídrico de bacias hidrográficas - Estudo de casos no quadrilátero ferrífero (MG). Dissertação de Mestrado, Departamento de Geologia, Universidade Federal de Ouro Preto, 172p.

COSTA F.M., BACELLAR L.A.P. 2007. Analysis of the influence of gully erosion in the flow pattern of catchment streams, Southeastern Brazil. CATENA; 69: 230-238.

CPRM 2009. Carta Geológica do Brasil ao Milionésimo, escala 1:1.000.000. Companhia de Recursos Minerais.. Disponível em http://www.cprm.gov.br/publique/cgi/cgilua.exe/sys/start. htm?sid=26 Acessado em 15/05/09.
CRUZ, W.B. 1995. Diagnóstico Hidrogeológico. In: IGA/CETEC/ SAE-PR, Desenvolvimento ambiental de Ouro Preto Microbacia do Ribeirão do Funil. Relatório Técnico Final de Projeto de Pesquisa, pp.: v1-v34.

CUSTODIO E. \& LLAMAS M.R. 1976. Hidrologia Subterrânea. Ediciones Omega S.A., Barcelona.

DEWANDEL B.; LACHASSAGNE P.; BAKALOWICZ M.; Weng P.H \& Al-Malki A. 2003. Evaluation of aquifer thickness by analyzing recession hydrographs. Application to the Oman ophiolite hard-rock aquifer. Journal of Hydrology; 274: 248-269.

DORR, J.V.N. 1969. Physiographic, stratigraphic and structural development of Quadrilátero Ferrífero, Brazil. U.S.Geological Survey Professional Paper; 641: 110p.

DUTRA V. F., MESSIAS M. C. T. B \& Garcia F. C. P. 2006. Papilionoideae (Leguminosae) nos Campos Ferruginosos do Parque Estadual do Itacolomi, Minas Gerais, Brasil: florística e fenologia. Revista Brasileira de Botânica; 28: 493-504.

FERREIRA A. F. \& LAZARIN H. A. 1993. Caracterização litoestrutural e geomorfológica da região do Pico do Itacolomi, Ouro Preto. Monografia de Graduação, Departamento de Geologia, Universidade Federal de Ouro Preto, 54p.

FERREIRA, Q. C. G. 2009. Diagnóstico Preliminar das Condições Hidrogeológicas do unicípio de Ouro Preto. Monografia de Final de Curso. UFOP/EM/DEAMB. Ouro reto, 133p.

IGAM - Instituto Mineiro de Gestão de Águas 2001. Avaliação das interferências ambientais da mineração nos recursos hídricos na bacia do Alto Rio das Velhas..

ANA/GEF/PNUMA/OEA. Subprojeto 1.2. Relatório Executivo Final, Belo Horizonte, 135p.

IBRAM - Instituto Brasileiro de Mineração. 2003. Contribuição do IBRAM para o zoneamento ecológico-econômico e o planejamento ambiental de municípios integrantes da APA-SUL RMBH. v.1. Itabirito, 245 p.

IBGE - INSTITUTO BRASILEIRO DE GEOGRAFIA E ESTATÍSTICA. Contagem populacional 2007. Disponível em: $<$ http://www.ibge.gov.br>. Acessado em 08 de evereiro de 2009.

KRESIC N. 1997. Quantitative solutions in hydrogeology and groundwater modeling. Florida, Ed. CRC. MS - Ministério da Saúde 2004. Portaria 518/2004. Padrão de potabilidade da água para consumo humano. Agência de Vigilância Sanitária, Brasília.

MARSHAK, S.\& ALKMIM, F.F. 1989. Proterozoic extension/ contraction of the sourther São

FRANCISCO CRATON, MINAS GERAIS, BRAZIL. TECTONICS. $8(3): 355-571$

PIMENTEL H. 2001. Caracterização Geoquímica da contaminação das águas na Serra de Ouro Preto, MG. Dissertação de Mestrado, Departamento de Geologia, Universidade Federal de Ouro Preto, $113 \mathrm{p}$.

RADAM BRASIL. 1983. Levantamento de Recursos Naturais. Vol.32. Folhas SF 23/24 (rio de Janeiro/Vitória).

RENGER F.E; NOCE C.M; ROMANO A.W; MACHADO N. 1994. Evolução sedimentar do Supergrupo Minas: 500Ma. de registro geológico no Quadrilátero Ferrífero, Minas Gerais, Brasil. Geonomos, 2(1):1-11.

SANTOS C.A; SOBREIRA F.G \& NETO A.L.C. 2002. Comportamento hidrológico superficial e erodibilidade dos solos da região de Santo Antônio do Leite, distrito de Ouro Preto - MG. Revista da Escola de Minas, 55 :285-290.

SILVA A.B; NETO A.F.S \& BERTACHINI A.C. 1994. Potencial das águas subterrâneas do Quadrilátero Ferrífero. In: ABAS, Congresso Brasileiro de águas subterrâneas, 8, nais, p.264-273.

SOBREIRO NETO A.F; BERTACHINI A.C; GIRADO A.C \& ALMEIDA D.C. 2001. Hidrogeological model of the Itabira iron ore district. In: IMWA Symposium, Belo Horizonte, p 1-13.

VARAJÃO C.A.C, 1991. A questão da correlação das superfícies de erosão do Quadrilátero Ferrífero , Minas Gerais. Revista Brasileira de Geociências; 21:138-145. 